\title{
The variations of Mo isotope composition of the Hongfenghu small catchment in Karst areas
}

\section{JIAN-MING ZHU ${ }^{1 *}$, WEN YANG ${ }^{1}$ AND XIANGLI WANG ${ }^{2,3}$}

1. State Key Laboratory of Geological Processes and Mineral Resources, China University of Geosciences (Beijing), Beijing 100083, China. ( *correspondence: jmzhu@cugb.edu.cn)

2. Department of Marine Sciences, University of South Alabama, Mobile, AL36688, USA. (xwang@southalabama.edu)

3. Dauphin Island Sea Lab, Dauphin Island, AL 36528, USA

The molybdenum (Mo) isotope systematics has been developed as a powerful proxy to reconstruct the extent of atmosphere-ocean oxygenation and the redox history of the local and global ocean ${ }^{[1]}$. Also, the isotopic composition of riverine Mo was reported to range widely from $\sim 0.00$ to $2.09 \%{ }^{[2]}$ relative to NIST SRM 3134 . However, the $\delta^{98 / 95}$ MoNIST3134 values of river water in Karst areas are poorly studied. Here, a suite of samples $(n=107)$ including river water, suspended particle, sediment, carbonate bedrocks and others were collected from the small Hongfenghu catchment, and their Mo isotope compositions were accurately and precisely determined by double spike MC-ICP-MS, in an attempt to understand the factors influencing the riverine Mo isotope behavior in Karst areas.

Molybdenum isotopic composition of river water in the four seasons ranges from 1.44 to $2.26 \%$ for Maiwen River, 1.34 to $1.59 \%$ for Yangchang River, 1.49 to $1.87 \%$ for Maxian River, and 1.06 to $1.62 \%$ for Houliu River. The $\delta^{98 / 95}$ Mo values in the bedrocks, soils, river sediments, suspended particles, and solid wastes from coal and its combustions were $0.50 \pm 0.28 \% \quad(n=4)$, $0.36 \pm 0.03 \%$ o $(\mathrm{n}=3), 0.35 \pm 0.25 \%$ \% $(\mathrm{n}=10), 0.24 \pm 0.16 \%$ o $(\mathrm{n}=14)$, and $1.36 \pm 0.21 \%$ o $(\mathrm{n}=3)$, respectively. Dominant water weeds were determined, with a $\delta^{98 / 95} \mathrm{Mo}$ of $0.36 \%$ for Spirogyra and $1.06 \%$ for black algae. All $\delta^{98 / 95} \mathrm{Mo}$ values in solid samples are clearly lower that in river water.

The average $\delta^{98 / 95}$ Mo value of rivers in this study are close to that of coal and shales, and Mo concentration has a positive correlation with $\mathrm{SO}_{4}{ }^{2-}$ in Maiwen River, indicating that some of Mo comes from the weathering of coal or shales. However, the $\delta^{98 / 95} \mathrm{Mo}$ of water collected from the dry season (Jan and Oct) are generally higher than those from the wet season (Apr and Jul). Domestic sewage shows the highest value $(2.26 \%$ ), with the similar concentrations to the river water. Our data show that: 1 ) river $\delta^{98 / 95} \mathrm{Mo}$ in karst areas varies seasonally; 2) catchment lithology has a significant influence; and 3) anthropogenic inputs may contribute to the variation of Mo isotopes in river water.

This work was granted by the National Natural Science Foundation of China (U1612441 and 41073017)

[1] Kendall et al. (2017) Rev. Mineral. Geochem. 82, 683-732. [2] Archer, C. and Vance, D. (2008). Nat. Geosci.1, 597-600. 